2020-05-04

\title{
Hereditary Cancer Syndrome Recognition and Testing: Beyond BRCA
}

Deborah O. Himes

Brigham Young University - Utah, deborah-himes@byu.edu

Hanford B. Shuman

Brigham Young University - Provo

Follow this and additional works at: https://scholarsarchive.byu.edu/facpub

Part of the Other Nursing Commons

\section{Original Publication Citation}

Shuman, H. B., \& Himes, D. O. (2020). Hereditary Cancer Syndrome Recognition and Testing:

Beyond BRCA. The Journal for Nurse Practitioners, 16(7), 517-522.

\section{BYU ScholarsArchive Citation}

Himes, Deborah O. and Shuman, Hanford B., "Hereditary Cancer Syndrome Recognition and Testing: Beyond BRCA" (2020). Faculty Publications. 5100.

https://scholarsarchive.byu.edu/facpub/5100

This Peer-Reviewed Article is brought to you for free and open access by BYU ScholarsArchive. It has been accepted for inclusion in Faculty Publications by an authorized administrator of BYU ScholarsArchive. For more information, please contact ellen_amatangelo@byu.edu. 


\title{
Hereditary Cancer Syndrome Recognition and Testing: Beyond BRCA
}

\author{
Deborah O. Himes, PhD, ANP-BC, Hanford B. Shuman, BSN, RN
}

Keywords:

Cowden hamartoma tumor syndrome

genetic testing

hereditary cancer syndrome

Li-Fraumeni syndrome

Peutz-Jeghers syndrome

primary care nurse practitioner

\begin{abstract}
A B S T R A C T
Hereditary cancer syndromes, resulting from mutations of tumor suppressor genes, can significantly increase the risk for breast cancer. Although hereditary breast and ovarian cancer syndrome caused by BRCA1/2 mutations is well-known, less well-known hereditary cancer syndromes also exist. This article focuses on 3 other syndromes, including Li-Fraumeni, Cowden, and Peutz-Jeghers. This article will help prepare nurse practitioners to recognize key clinical features of these syndromes and understand testing criteria. Additionally, this article discusses barriers to diagnosing hereditary cancer syndromes and the role of primary care nurse practitioners in ordering genetic tests and making genetic referrals for optimal patient care.
\end{abstract}

(c) 2020 Elsevier Inc. All rights reserved.
More than 50 hereditary cancer syndromes (HCSs) have been identified and contribute to the development of $5 \%$ to $10 \%$ of all cancers. ${ }^{1}$ Most clinicians have a basic knowledge and awareness of BRCA1 and BRCA2 gene mutations as major causes of the HCS known as hereditary breast and ovarian cancer syndrome. However, other gene mutations leading to other HCSs also increase the risk for breast cancer. Examples of these syndromes include LiFraumeni syndrome (LFS), Cowden hamartoma tumor syndrome or Cowden syndrome (CS), and Peutz-Jeghers syndrome (PJS) ${ }^{2}$ (Table 1). Although uncommon, each of these syndromes poses risks to individuals who inherit related mutations. Because they are uncommon, many patients may go undiagnosed for years, minimizing their ability to reduce risk.

Primary care providers (PCPs), including nurse practitioners (NPs), are gatekeepers in health care. Patients depend on PCPs' expertise to guide them through the network of specialties and resources needed to treat and prevent diseases. Primary care NPs must be prepared to identify patients at risk for HCSs, order genetic testing when appropriate, and properly refer patients to genetic counselors.

Patients rely on PCPs for guidance about genetic risk and testing; however, PCPs' knowledge of HCSs may be limited because many are rare diseases only recently discovered and described. PCPs have been found to both under- and overtest. For example, in the years after the discovery of BRCA-related HBOC, PCPs have struggled to correctly identify, test, and refer at-risk patients. ${ }^{3-6}$ Although many PCPs are aware of BRCA testing, few have ordered it. ${ }^{5}$ Approximately $90 \%$ of high-risk women meeting United States Preventive Services Task Force criteria for counseling referral and testing have reported sharing their risk factors with their PCPs, yet only 20\% were actually referred, and $8 \%$ were tested. ${ }^{3}$ In contrast, many average-risk women not meeting criteria for genetic counseling or BRCA testing have been offered counseling and/or testing. ${ }^{6}$

Both under- and overtesting and referral for counseling can be problematic. The lack of understanding about HCSs is an additional problem. In a study published in 2017, 44\% of PCPs reported routinely referring patients for genetic counseling; despite making referrals, most of them showed deficits in their understanding of HBOC. 4

Despite knowledge limitations, $81.5 \%$ of PCPs reported high interest in HBOC education. ${ }^{4}$ Researchers have called for educational programs to "focus on narrowing the knowledge gap between basic genetics and clinical medicine, because identification of individuals at risk for HBOC [and other HCSs] is a critical first step to ensuring access to cancer genetics services and risk reducing interventions." 4 The aim of this article was to inform primary care NPs about clinical characteristics and testing criteria for 3 HCSs associated with breast cancer and to encourage early recognition, appropriate genetic testing, and referral for genetic services.

\section{Li-Fraumeni Syndrome (LFS)}

LFS is a rare autosomal dominant HCS associated with germline mutations in TP53, a cancer suppressor gene, which codes for the p53 tumor suppressor protein. ${ }^{15}$ LFS was originally described by Li and Fraumeni in 1969 while analyzing families with childhood rhabdomyosarcoma. TP53 mutations are highly penetrant, with a cumulative lifetime risk for developing some type of cancer at nearly $100 \%$ by 70 years old and an $85 \%$ cumulative lifetime risk of developing breast cancer by 60 years old. ${ }^{2,9}$

LFS predisposes individuals to soft tissue sarcomas, osteosarcomas, breast cancer, colon cancer, gastric cancer, adrenocortical 
Table 1

Comparison of Autosomal Dominant Hereditary Cancer Syndromes Associated With Breast Cancer

\begin{tabular}{|c|c|c|c|c|}
\hline Syndrome & $\begin{array}{l}\text { Associated Tumor } \\
\text { Suppressor Gene }\end{array}$ & $\begin{array}{l}\text { Lifetime Risk for Breast } \\
\text { Cancer with Syndrome }\end{array}$ & $\begin{array}{l}\text { Other Malignancies/ } \\
\text { Conditions in Syndrome }\end{array}$ & De Novo Rate \\
\hline \multirow[t]{2}{*}{$\begin{array}{l}\text { Hereditary breast and ovarian } \\
\text { cancer syndrome }\end{array}$} & BRCA1 & $46 \%-87 \%^{7}$ & $\begin{array}{l}\text { Ovarian } \\
\text { Prostate } \\
\text { Pancreatic }\end{array}$ & $<5 \%^{7}$ \\
\hline & BRCA2 & $38 \%-84 \%^{7}$ & $\begin{array}{l}\text { Ovarian } \\
\text { Prostate } \\
\text { Pancreatic } \\
\text { Melanoma }^{8}\end{array}$ & $<5 \%^{7}$ \\
\hline Li-Fraumeni syndrome & TP53 & $85 \%^{9}$ & $\begin{array}{l}\text { Soft tissue sarcomas } \\
\text { Osteosarcomas } \\
\text { Colon cancer } \\
\text { Gastric cancer } \\
\text { Adrenocortical carcinoma } \\
\text { Brain tumors }^{9}\end{array}$ & $7 \%-20 \%{ }^{10}$ \\
\hline Cowden syndrome & PTEN & $85 \%^{11}$ & $\begin{array}{l}\text { Thyroid disease } \\
\text { Thyroid cancer } \\
\text { Macrocephaly } \\
\text { Paired organ cancer } \\
\text { Endometrial cancer } \\
\text { Brain tumors } \\
\text { Vascular malformations } \\
\text { Mucocutaneous lesions }\end{array}$ & $10.7 \%-47.6 \%{ }^{12}$ \\
\hline Peutz-Jeghers syndrome (PJS) & STK11 & $45 \%^{13}$ & $\begin{array}{l}\text { Gastrointestinal } \\
\text { hamartomatous polyps } \\
\text { Gastrointestinal cancer } \\
\text { Pancreatic cancer } \\
\text { Cervical cancer } \\
\text { Ovarian cancer }^{2}\end{array}$ & $\begin{array}{l}\text { Unknown, approximately } 45 \% \text { of affected individuals } \\
\text { have no family history of } \text { PJS }^{14}\end{array}$ \\
\hline
\end{tabular}

carcinoma, and brain tumors. Approximately $1 \%$ of all hereditary breast cancer cases are attributed to the presence of a TP53 gene mutation. ${ }^{16}$ The syndrome is characterized by the development of certain cancers at ages earlier than expected. For example, of all breast cancers and soft tissue sarcomas associated with LFS, 80\% develop before 45 years old. ${ }^{17}$ Women appear to be more prone to any early cancer with a $50 \%$ chance by 31 years old and $90 \%$ to $100 \%$ by 60 years old. In comparison, men exhibit a 50\% chance of any cancer development by 46 years old and a $73 \%$ lifetime risk. ${ }^{9}$

In some cases, cancer onset occurs especially early. Frequently, children with LFS are found with soft tissue sarcomas, brain tumors, and adrenocortical carcinomas. ${ }^{2}$ Studies have suggested a higher prevalence of individuals with germline TP53 mutations than previously thought, between 1 in 5,000 and 1 in $20,000 .^{18,19}$ It is suspected that there are other mutations that may also be responsible for LFS characteristics.

\section{Identifying Patients for LFS Genetic Testing}

The National Comprehensive Cancer Network (NCCN) recommends using a combination of 2 sets of criteria to select patients for LFS testing: classic LFS criteria and Chompret criteria ${ }^{2}$ (Table 2). Chompret criteria can be met regardless of family history, allowing for the detection of de novo TP53 germline variants that would be missed using classic LFS criteria alone. ${ }^{20,21}$ When both sets of criteria are used together, sensitivity increases to $95 \%$ from the estimated $40 \%$ that is seen with the use of classic LFS criteria alone. $^{18}$

Testing may also be considered for patients who do not meet classic LFS or Chompret criteria. TP53 germline mutations are commonly found in women with early-onset breast cancer; $3 \%$ to $8 \%$ of those with breast cancer before 30 years old with no family history have TP53 mutations. ${ }^{18}$ Thus, the NCCN recommends that women who develop breast cancer before 30 years old be considered for testing. ${ }^{2}$ Cancer survivors should be tested because if they carry a harmful mutation, having this knowledge will qualify them for intensive cancer surveillance so that future cancers may be caught at earlier stages. Similarly, any person having a first-degree blood relative with a known TP53 mutation should be considered for testing.

\section{Cowden Syndrome (CS)}

CS is a disorder inherited in an autosomal dominant pattern that predisposes individuals to a number of conditions and cancers, including breast cancer, thyroid disease, thyroid cancer, macrocephaly, paired organ cancer, endometrial cancer, brain tumors, vascular malformations, and various mucocutaneous lesions. ${ }^{2}$ Lloyd and Dennis ${ }^{23}$ were the first to identify CS based on the unique clinical findings of a 20-year-old woman with the surname of Cowden.

The syndrome most often stems from a germline pathogenic mutation in the PTEN tumor suppressor gene (approximately $85 \%$ of the time), but other gene mutations are also suspected to cause CS. ${ }^{1}$ PTEN germline mutations do not always result in CS. Rather, CS is 1 of multiple syndromes associated with PTEN mutations, including Bannayan-Riley-Ruvalcaba syndrome, Proteus syndrome, adult Lhermitte-Duclos disease, and autism spectrum disorders with macrocephaly. However, these other syndromes are not typically associated with breast cancer. Collectively, this spectrum of disorders is known as the PTEN hamartoma tumor syndrome (PHTS).

CS itself is understood to occur in about 1 in 200,000 people; however, considering the challenge of accurate clinical diagnosis, this figure is likely an underestimate. ${ }^{2,24}$ Penetrance is usually high at $80 \%$. Multiple tumorlike hamartoma lesions with an associated increased risk for multiple cancers characterize CS. Breast cancer is the most frequently found malignancy in $\mathrm{CS}^{24}$ Women with CS have an $85 \%$ lifetime risk of developing breast cancer, with an average age of 38 to 46 years at diagnosis. ${ }^{11}$ Hamartomas form most frequently on the skin and mucous membranes. Other common 
Table 2

Li-Fraumeni Syndrome (LFS) Testing Criteria

\begin{tabular}{|c|c|c|}
\hline Classic LFS Criteria $^{22}$ & Chompret Criteria ${ }^{20,21}$ & Additional NCCN Recommendations ${ }^{2}$ \\
\hline $\begin{array}{l}\text { Any individual diagnosed with sarcoma under age } 45 \text { years with } \\
\text { - One first-degree relative diagnosed with cancer under } \\
\text { age } 45 \text { years AND } \\
\text { - One additional first- or second-degree relative diagnosed } \\
\text { with cancer under age } 45 \text { years or sarcoma at any age }\end{array}$ & $\begin{array}{l}\text { Any individual with multiple primary } \\
\text { tumors under age } 36 \text { years, including } \\
\text { at least } 2 \text { of the following } \\
\text { - Sarcoma } \\
\text { - Breast cancer } \\
\text { - Adrenocortical carcinoma } \\
\text { - Brain tumor OR adrenocortical carcinoma at any age }\end{array}$ & $\begin{array}{l}\text { Any individual with breast cancer } \\
\text { before } 30 \text { years old } \\
\text { Any individual with a blood relative } \\
\text { diagnosed with p53 mutation }\end{array}$ \\
\hline
\end{tabular}

$\mathrm{NCCN}=$ National Comprehensive Cancer Network.

sites include the breast, thyroid, endometrium, and brain. ${ }^{2}$ Benign mucocutaneous lesions occur in an estimated 99\% of individuals with CS, and most often manifest in patients in their $20 \mathrm{~s}^{25}$ Gastrointestinal polyps occur in most patients. Patients with CS may present with a number of different lesions (Table 3); thyroid disorders like multinodular goiter, adenomatous nodules, and follicular adenomas are common, and lifetime risk for thyroid cancer is approximately $3 \%$ to $10 \%{ }^{2}$

Macrocephaly, defined as having a head circumference in the 97th percentile, or $58 \mathrm{~cm}$ for females and $60 \mathrm{~cm}$ for males, is an especially common manifestation in CS, occurring in $80 \%$ to $100 \%$ of patients. $^{26,27}$ Strong associations have been found between CS and Lhermitte-Duclos disease and autism spectrum disorder characterized by macrocephaly. ${ }^{28}$ Patients with CS exhibit some risk of developing endometrial cancer, brain tumors, vascular malformations, and colon cancer. ${ }^{2}$ The cumulative risk for developing any cancer and/or Lhermitte-Duclos disease by 60 years old is estimated to be $56 \%$ for men and $87 \%$ for women. ${ }^{29}$

\section{Identifying Patients for CS Genetic Testing}

The $\mathrm{NCCN}^{2}$ suggests the use of 3 sets of criteria and various combinations of each to evaluate the need for genetic testing for CS (Table 3). The first criteria set includes individuals meeting diagnostic criteria for CS with a history of certain diagnoses or a family history positive for a known PTEN mutation. The second and third criteria sets include identified "major" and "minor" features of CS. ${ }^{2}$ Patients may meet different combinations of these categorized criteria and are considered to meet threshold criteria if they meet any of the conditions listed in Table 3. Testing may also be considered for those not meeting criteria with symptoms of concern, suggestive personal cancer histories, or suggestive family histories. $^{2}$

\section{Peutz-Jeghers Syndrome (PJS)}

PJS is an autosomal dominant HCS most often caused by a mutation in the STK11 tumor suppressor gene. Few cases characteristic of PJS have been identified without this mutation. Gastrointestinal hamartomatous polyps, most frequently in the stomach and intestines, are characteristic of PJS. Hamartomas are benign tumors made of an abnormal mixture of tissue that are normally found in the area where they grow. In children, darkly pigmented spots can often be found on the oral mucosa and around the eyes, nostrils, and anus. These spots often fade with age. When asked, young adults may recall the presence of these spots during childhood.

PJS greatly increases an individual's risk for gastrointestinal, pancreatic, cervical, ovarian, and breast cancers. The prevalence of PJS is estimated to be between 1 in 25,000 and 1 in $300,000 .^{30}$ Penetrance in affected individuals is high. The risk for developing any first cancer has been shown to be $2 \%$ by age 20 years and increases gradually with age to reach $85 \%$ by 70 years old. ${ }^{13}$ In addition, women with PJS have an increased risk for developing breast cancer (ie, $8 \%$ by 40 years old and increasing to $45 \%$ by 70 years old $)^{13}$

\section{Identifying Patients for PJS Genetic Testing}

PJS should be suspected in individuals presenting with 2 or more PJS-type intestinal polyps, mucocutaneous macules, gynecomastia in males as a result of estrogen-producing Sertoli cell testicular tumors, or a history of intussusception (especially in a child or young adult). ${ }^{14}$ Testing for PJS is recommended when an individual meets any 1 of 4 conditions in listed in Table 4. Additionally, testing may be considered when patients present with other concerning symptoms or histories under circumstances in which these criteria are not met.

\section{Barriers to Identification of HCS}

Beyond the need for further PCP education, other barriers to HCS patient detection and counseling exist. These include incomplete collection and assessment of family histories, time constraints, patient perceptions and beliefs, limited patient knowledge, and financial concerns. Although most providers collect family histories with all patients, family histories are often incomplete and not routinely assessed for genetic risk factors. It is important to recognize that family history collection should not be a 1-time event because family histories are ever changing. ${ }^{32}$ Time constraints and other pressures may limit complete collection and assessment. Even with electronic family history-taking tools that allow patients to electronically enter their own family history information and give providers organized pedigree and risk information, providers have been found to only refer $54 \%$ of those for whom a genetic counseling referral is recommended. ${ }^{33}$

Although providers experience barriers to making genetic referrals, patients also experience barriers to receiving genetic counseling and testing after being referred by a PCP. Only $8 \%$ of women identified by family history as high risk for hereditary breast cancer went to a genetic counseling appointment within 1 year of receiving a referral. ${ }^{34}$ Among women who did not go through with a genetic counseling appointment, 3 main barriers were identified. First, patient-held perceptions may prevent followthrough with referrals. For example, patients might not perceive urgency or benefit to undergoing counseling; patients may not believe they are at risk or believe that breast cancer in their families was due to genetic causes. Second, women lacked knowledge about genetic counseling and its purpose. Women worried about the complexity of genetic services and feared the possibility of a positive test. Third, women worried about financial challenges. They feared genetic counseling would bring high costs of testing and management, cause challenges dealing with insurance companies, and result in insurance discrimination. ${ }^{34}$ Many women of this study also discussed the fact that their PCP, when presented with a letter 
Table 3

Cowden Syndrome (CS) Testing Criteria

Individuals meeting any of the following warrant testing:

- Meets at least 1 stand-alone criteria

- 2 or more major criteria with 1 being macrocephaly

- 3 or more major criteria without 1 being macrocephaly

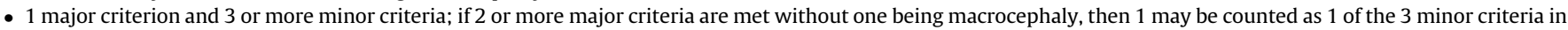
this case

- 1 or more major criteria or 2 or more minor criteria AND a relative diagnosed with CS/PHTS or Bannayan-Riley-Ruvalcaba syndrome

\begin{tabular}{|c|c|c|}
\hline Stand-alone Criteria & Major Criteria & Minor Criteria \\
\hline $\begin{array}{l}\text { Meets diagnostic criteria for CS } \\
\text { History of Bannayan-Riley-Ruvalcaba syndrome } \\
\text { History of adult Lhermitte-Duclos disease } \\
\text { Autism spectrum disorder with macrocephaly } \\
2 \text { or more biopsy-proven trichilemmomas } \\
\text { Family history with a known PTEN mutation }\end{array}$ & $\begin{array}{l}\text { Breast cancer } \\
\text { Macrocephaly } \\
\text { Endometrial cancer } \\
\text { Follicular thyroid cancer } \\
\text { Multiple gastrointestinal hamartomas or ganglioneuromas } \\
\text { Macular pigmentation of glans penis } \\
\text { Mucocutaneous lesions (trichilemmomas, palmoplantar keratoses, oral mucosal } \\
\text { papillomatoses, cutaneous facial papules) }\end{array}$ & $\begin{array}{l}\text { Autism spectrum disorder without } \\
\text { macrocephaly } \\
\text { Colon cancer } \\
\text { Esophageal glycogenic acanthosis, } \\
3 \text { or more lipomas } \\
\text { Intellectual disability } \\
\text { Papillary thyroid cancer, papillary or } \\
\text { follicular variant } \\
\text { Other thyroid structural lesions } \\
\text { (adenoma, nodules, goiter, etc) } \\
\text { Renal cell carcinoma } \\
\text { One gastrointestinal hamartoma or } \\
\text { ganglioneuroma } \\
\text { Testicular lipomatosis } \\
\text { Vascular anomalies }\end{array}$ \\
\hline
\end{tabular}

PHTS $=$ PTEN harmatoma tumor syndrome.

Table 4

Peutz-Jeghers Syndrome (PJS) Testing Criteria

Individuals meeting any 1 of the following criteria should be tested ${ }^{31}$ :

- More than 2 histologically confirmed PJS-type hamartomatous gastrointestinal polyps

- Any number of PJS-type polyps with a family history of PJS in close relatives

- Characteristic mucocutaneous pigmentation with a family history of PJS in close relatives

- Any number of PJS-type polyps along with characteristic mucocutaneous pigmentation

identifying high risk based on family history taken during screening mammograms, were often dismissive of the letter or ignored it completely and did not recommend genetic counseling. ${ }^{34}$

Although patients experience multiple barriers, certain factors have proven to motivate and facilitate their decision to seek genetic counseling and testing. Most importantly, more verbal discussion with PCPs, along with more written information and a strong recommendation for counseling, encourage the uptake of counseling and testing. ${ }^{34}$ Thus, PCPs play an important role in helping high-risk women receive genetic counseling services and testing. They must be thorough in collecting and assessing family histories, well versed in basic genetics, ready to educate and provide information, and highly encouraging of genetic counseling services.

\section{PCP-NP Role in Genetic Testing}

Genetic counselors are experts in reviewing pedigrees, selecting genetic tests, and providing pre- and posttest counseling. However, relying exclusively on genetic counselors to recommend genetic testing presents a dilemma. Currently in the US, there are only 4,000 genetic counselors, less than 1 counselor per 80,000 people living in the US. ${ }^{35}$ Because of challenges finding a counselor and wait times for visits, individuals needing services may opt not to follow through with referrals. If they decide to be seen, they may wait months for an appointment. Another option is for PCPs to provide appropriate pretest counseling and order genetic testing for high-risk individuals before meeting with genetic counselors. Patients with positive findings could then attend genetic counseling appointment with results in hand, allowing for much faster adoption of risk-reducing and screening interventions.
A process intervention study assessing the integration of routine hereditary cancer risk assessment, counseling, and genetic testing in obstetrics/gynecology practices found it is feasible to incorporate hereditary cancer risk assessment, education, and testing into community obstetrics and gynecology practices. ${ }^{36}$ In this study, obstetrics/gynecology providers were appropriately trained and acted competently in assessing risk and ordering tests. Both providers and patients reported high levels of confidence and satisfaction with the process, and the number of patients who underwent genetic testing increased 8-fold over the previous year. ${ }^{36}$ This finding implies that during the previous year many patients who would have qualified for genetic testing and would have accepted it did not receive that option. As PCPs develop knowledge and skills in assessing family pedigrees for genetic risk and ordering genetic tests with appropriate pretest counseling, more patients will benefit from receiving personalized risk information.

\section{Multigene Panel Testing}

PCPs should consider the utility of ordering multigene panel testing as opposed to single-gene testing. Previously, single-gene testing has been standard practice. However, multigene panel testing can be more efficacious for several reasons. Primarily, less common HCSs, such as the 3 discussed in this article, may go undetected for great lengths of time if PCPs order single-gene tests. Multigene panel testing has the ability to identify significant cancer risks that otherwise would not be recognized, and it enables appropriate risk-reducing medical management decisions. ${ }^{36}$ In studies of women already diagnosed with breast cancer, half of all 
pathogenic variants identified among individuals meeting $\mathrm{HBOC}$ criteria were in genes other than BRCA1/2. In other words, panel testing revealed twice as many women with genetic risk for breast cancer than single-gene testing for BRCA1/2 would have. ${ }^{37,38}$ Panel testing allows for quicker diagnosis of HCSs and thus greater opportunity for risk-reducing surveillance and potentially greater uptake of genetic counseling services.

\section{Resources for PCPs and Patients}

Many online resources are available for PCPs and patients to help them understand HCSs. The NCCN can be accessed at www. nccn.org. Practitioners must register for a free account. Once registered, practitioners have access to many guidelines. The guideline titled "Genetic/Familial High-Risk Assessment: Breast, Ovarian, and Pancreatic" has information about all cancer syndromes discussed in this article and more. The NCCN website also has patient education resources. Another online resource is Cancer. Net published by the American Society of Clinical Oncology. A search on hereditary cancer-related syndromes will bring up a list of syndromes including those discussed in this article. Both of these organizations use expert panels to compile information and update their publications regularly.

\section{Conclusion}

Various HCSs beyond BRCA-related HBOC predispose many individuals to breast and other cancers. As gatekeepers of health care, primary care NPs must be prepared to identify patients at risk for HCSs and guide them through genetic testing, referral, and followup care. Multiple provider and patient factors act as barriers to the use of genetic resources. Among other barriers, limitations in provider knowledge and understanding of genetic disorders prove to be a prominent barrier, but most providers express high interest in learning more about genetic principles and HCSs. Because of barriers, many high-risk patients who have inherited an HCS may be currently undiagnosed, thus inhibiting the ability to initiate riskreducing measures. In this article, 3 less common HCSs, their etiologies, and recommended testing criteria have been reviewed in an effort to inform provider practice. Because genetic counselor availability is limited, PCPs have the opportunity to be a valuable genetics resource for many individuals. Primary care NPs should identify patients with presentations and family histories consistent with HCSs and either offer pretest counseling and order multigene panel testing or refer at-risk people to genetic counseling. Finally, all patients with positive findings should be referred for genetic counseling for support and recommendations on prevention and screening.

\section{References}

1. PDQ Cancer Genetics Editoral Board. Genetics of breast and gynecologic cancers $(P D Q \otimes)$ : health professional version. PDQ cancer information summaries; Published October 18, 2019, https://www.ncbi.nlm.nih.gov/books/NBK65767/. Accessed.

2. National Comprehensive Cancer Network. Genetic/familial high-risk assessment: breast, ovarian, and pancreatic. NCCN clinical practice guidelines in oncology (NCCN Guidelines $\left.{ }^{\circledR}\right)$; Published December 4, 2019, https://www. nccn.org/. Accessed.

3. Bellcross CA, Leadbetter S, Alford SH, Peipins LA. Prevalence and healthcare actions of women in a large health system with a family history meeting the 2005 USPSTF recommendation for BRCA genetic counseling referral. Cancer Epidemiol Biomarkers Prev. 2013;22(4):728-735.

4. Nair N, Bellcross C, Haddad L, et al. Georgia primary care providers' knowledge of hereditary breast and ovarian cancer syndrome. J Cancer Educ. 2017;32(1): 119-124.

5. Bellcross CA, Kolor K, Goddard KA, Coates RJ, Reyes M, Khoury MJ. Awareness and utilization of BRCA1/2 testing among U.S. primary care physicians. Am J Prev Med. 2011;40(1):61-66.
6. Trivers KF, Baldwin LM, Miller JW, et al. Reported referral for genetic counseling or BRCA $1 / 2$ testing among United States physicians. Cancer. 2011;117(23):5334-5343.

7. Petrucelli N, Daly MB, Feldman GL. Hereditary breast and ovarian cancer due to mutations in BRCA1 and BRCA2. Genet Med. 2010;12(5):245-259.

8. Petrucelli N, Daly MB, Pal T. BRCA1- and BRCA2-associated hereditary breast and ovarian cancer. GeneReviews. Seattle, WA: University of Washington, Seattle; 2016. https://www.ncbi.nlm.nih.gov/books/NBK1247/. Accessed January 16, 2020.

9. Mai PL, Best AF, Peters JA, et al. Risks of first and subsequent cancers among TP53 mutation carriers in the National Cancer Institute Li-Fraumeni syndrome cohort. Cancer. 2016;122(23):3673-3681.

10. Schneider K, Zelley K, Nichols KE, Garber J. Li-Fraumeni Syndrome, GeneReviews. Seattle, WA: University of Washington; 1999. https://www.ncbi.nlm. nih.gov/books/NBK1311/. Accessed January 16, 2020.

11. Eng C. PTEN hamartoma tumor syndrome. GeneReviews. Seattle, WA: University of Washington; 2001. https://www.ncbi.nlm.nih.gov/books/NBK1488/. Accessed January 16, 2020.

12. Mester J, Eng C. Estimate of de novo mutation frequency in probands with PTEN hamartoma tumor syndrome. Genet Med. 2012;14(9):819-822.

13. Hearle N, Schumacher V, Menko FH, et al. Frequency and spectrum of cancers in the Peutz-Jeghers syndrome. Clin Cancer Res. 2006;12(10):3209-3215.

14. McGarrity TJ, Amos CI, Baker MJ. Peutz-Jeghers syndrome. GeneReviews. Seattle, WA: University of Washington; 2001. https://www.ncbi.nlm.nih.gov/ books/NBK1266/. Accessed January 16, 2020.

15. Nandikolla AG, Venugopal S, Anampa J. Breast cancer in patients with LiFraumeni syndrome - a case-series study and review of literature. Breast Cancer (Dove Med Press). 2017;9:207-215.

16. Sidransky D, Tokino T, Helzlsouer $\mathrm{K}$, et al. Inherited p53 gene mutations in breast cancer. Cancer Res. 1992;52(10):2984-2986.

17. Vogel WH. Li-Fraumeni syndrome. J Adv Pract Oncol. 2017;8(7):742-746.

18. Gonzalez KD, Noltner KA, Buzin $\mathrm{CH}$, et al. Beyond Li Fraumeni syndrome: clinical characteristics of families with p53 germline mutations. J Clin Oncol. 2009;27(8):1250-1256.

19. Lalloo F, Varley J, Ellis D, et al. Prediction of pathogenic mutations in patients with early-onset breast cancer by family history. Lancet. 2003;361(9363): 1101-1102.

20. Chompret A, Abel A, Stoppa-Lyonnet D, et al. Sensitivity and predictive value of criteria for p53 germline mutation screening. J Med Genet. 2001;38(1): 43-47.

21. Tinat J, Bougeard G, Baert-Desurmont S, et al. 2009 version of the Chompret criteria for Li Fraumeni syndrome. J Clin Oncol. 2009;27(26):e108-e109; author reply e110.

22. Li FP, Fraumeni JF Jr, Mulvihill JJ, et al. A cancer family syndrome in twentyfour kindreds. Cancer Res. 1988;48(18):5358-5362.

23. Lloyd KM 2nd, Dennis M. Cowden's disease. A possible new symptom complex with multiple system involvement. Ann Intern Med. 1963;58:136-142.

24. Nelen MR, Kremer H, Konings IB, et al. Novel PTEN mutations in patients with Cowden disease: absence of clear genotype-phenotype correlations. Eur J Hum Genet. 1999;7(3):267-273.

25. Pilarski R, Eng C. Will the real Cowden syndrome please stand up (gain)? Expanding mutational and clinical spectra of the PTEN hamartoma tumour syndrome. J Med Genet. 2004;41(5):323-326.

26. Pilarski R, Burt R, Kohlman W, Pho L, Shannon KM, Swisher E. Cowden syndrome and the PTEN hamartoma tumor syndrome: systematic review and revised diagnostic criteria. J Natl Cancer Inst. 2013;105(21):1607-1616.

27. Roche AF, Mukherjee D, Guo SM, Moore WM. Head circumference reference data: birth to 18 years. Pediatrics. 1987;79(5):706-712.

28. Zhou XP, Waite KA, Pilarski R, et al. Germline PTEN promoter mutations and deletions in Cowden/Bannayan-Riley-Ruvalcaba syndrome result in aberrant PTEN protein and dysregulation of the phosphoinositol-3-kinase/Akt pathway. Am J Hum Genet. 2003;73(2):404-411.

29. Nieuwenhuis MH, Kets CM, Murphy-Ryan M, et al. Cancer risk and genotypephenotype correlations in PTEN hamartoma tumor syndrome. Fam Cancer. 2014;13(1):57-63.

30. US National Library of Medicine, Peutz-Jeghers syndrome. Genetics Home Reference. Bethesda, MD: National Institutes of Health; 2013.

31. Beggs AD, Latchford AR, Vasen HF, et al. Peutz-Jeghers syndrome: a systematic review and recommendations for management. Gut. 2010;59(7):975-986.

32. McReynolds K, Lewis S. Genetic counseling for hereditary cancer: a primer for NPs. Nurse Pract. 2017;42(7):22-28.

33. Buchanan AH, Christianson CA, Himmel T, et al. Use of a patient-entered family health history tool with decision support in primary care: impact of identification of increased risk patients on genetic counseling attendance. J Genetic Couns. 2015;24(1):179-188.

34. Kne $\mathrm{A}$, Zierhut $\mathrm{H}$, Baldinger $\mathrm{S}$, et al. Why is cancer genetic counseling underutilized by women identified as at risk for hereditary breast cancer? Patient perceptions of barriers following a referral letter. J Genetic Couns. 2017;26(4):697-715.

35. Bookman T. A shortage of genetic counselors in the Atlantic. Kaiser Health News. April 21, 2016. https://www.theatlantic.com/health/archive/2016/04/ shortage-of-genetic-counselors/478815/. Accessed January 1, 2020.

36. DeFrancesco MS, Waldman RN, Pearlstone MM, et al. Hereditary cancer risk assessment and genetic testing in the community-practice setting. Obstet Gynecol. 2018;132(5):1121-1129. 
37. Rosenthal ET, Bernhisel R, Brown K, Kidd J, Manley S. Clinical testing with a panel of 25 genes associated with increased cancer risk results in a significant increase in clinically significant findings across a broad range of cancer histories. Cancer Genet. 2017;218-219:58-68.

38. Buys SS, Sandbach JF, Gammon A, et al. A study of over 35,000 women with breast cancer tested with a 25-gene panel of hereditary cancer genes. Cancer. 2017;123(10):1721-1730.
Deborah O. Himes, PhD, ANP-BC, is an assistant professor at Brigham Young University College of Nursing in Provo, UT, and can be contacted at deborah-himes@byu.edu. Hanford B. Shuman, BSN, RN, is a graduate student at Brigham Young University College of Nursing.

In compliance with national ethical guidelines, the authors report no relationships with business or industry that would pose a conflict of interest. 